\section{Over the fields}

\section{Tom Blunde/l}

Journal of Molecular Recognition. Editorin-chief Irwin M. Chaiken. Heyden. 6/yr. UK and Europe £149; North America $\$ 253$.

Molf:AU.AR recognition mediates information storage, replication and transfer in all biological systems. What then is the specific role of the Journal of Molecular Recognition when the subject pervades all areas of biology?

According to the information for authors, the journal is a "multidisciplinary publication devoted to research on the basic principles, characterisation and application of specific interactions in biology, biotechnology and medicine". The journal certainly meets this broad remit. It has published interesting articles by distinguished authors on immunomagnetic separation technology, the insulin receptor, cognitive features in epitopes, mimetics of B-turns, the selfassembly of neurohypophyseal hormone precursors and binding sites for bleomycin on DNA. All involve molecular interactions and recognition. But in spite of the individual excellence of the articles, the journal has yet to identify a niche in the fast-expanding fields of molecular and cell biology. The lack of a 'self-assembling and casily recognized' group of authors appears to be reflected in the very long period - June 1988 to April 1989 between the third and fourth issues of Vol. 1.

Molecular recognition has been the topic of research in biophysical circles for many years. Fred Richards, David Phillips, Max Perutz and many others identified the importance of weak interactions involving the complementarity of surfaces, hydrogen bonds and ionic interactions in proteins two decades ago and set the scene for the theoretical analysis and quantification that has occurred since. Why then is it only in the past few years that government organizations and publishers have chanced upon the term 'molecular recognition' and exploited it with investment in new research initiatives and new journals?

The reason, in part, is the recruitment of large numbers of chemists and biologists into molecular and cell biology as a consequence of the success of recombinant DNA methodology and biophysical approaches to the three-dimensional structure of macromolecules. Much of the scientific community is new to the area even though the concepts are old. However, it is also a consequence of the emphasis on planning and themes that has recently characterized science policy even under the governments of free marketeers such as Margaret Thatcher and Ronald
Reagan. According to John Ziman, 'science in a steady state' requires more management and selection; the natural trend of science is to expand exponentially, as de Solla Price pointed out in 1963, but this is no longer possible. The new planning policies appear to have led to a proliferation of labels such as molecular recognition, biotransformations and protein enginecring for activities that already have a history.

The existence of the Journal of Molecular Recognition thus reflects changes in the nature of scientific policy making, and also the existence of new multidisciplinary communities. The challenge for the journal is to draw out of each topic the aspects of molecular recognition which may be relevant and of interest to the wider community in this diffuse area of science. Emphasis may be on technological advances which underpin the science, or on experimental or theoretical approaches that extend our understanding of the general principles of molecular

\section{JMR}

\section{MOLECULAR RECOGNITION}

recognition. On the basis of the first four issues, the journal has still some way to go before it can meet these ambitious objectives that are described by the editor but not widely manifested in the material published.

Tom Blundell is in the Imperial Cancer Research Fund Unit of Structural Molecular Biology, Department of Crystallography. Birkbeck College, Malet Street, London WC1E 7HX, UK.

\section{III treatment}

\section{Malcolm Rowland}

Advanced Drug Delivery Reviews. Editors-in-chief R. L. Juliano, G. Poste and E. Tomlinson. Elsevier. 6/yr. Dfl.888. Journal of Drug Development. Editor A. D. S. Caldwell. Gardiner-Caldwell, The Old Ribbon Mill, Pitt Street, Macclesfield, Cheshire SK11 7PT, UK. 4/yr. £85, \$140.

Tus dramatic discoveries arising out of cellular and molecular biology portend well for the emergence of new classes of therapcutic agents for the treatment of diseases that plague man, other animals and plants. As the editors of Advanced Drug Delivery Reviews correctly stress, however, these discoveries will not translate into effective treatments unless they

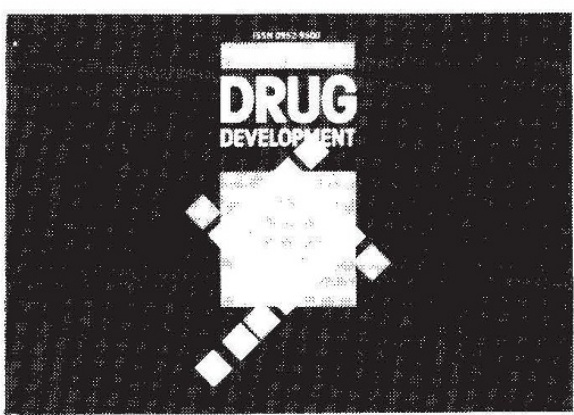

are matched by new strategies to achieve optimal delivery of the agents to their target sites. Innumerable promising entities have failed to reach the marketplace cither, for example, because of poor absorption from sites of administration, non-specific tissue distribution with unwanted toxicity, or because of failure to penetrate the target site.

The editors of the journal have recognized that the solution to problems in drug delivery requires an interdisciplinary approach and have rightly sought reviews that cover a wide range of areas in chemistry, biology and medicine. Emphasis has been on the newer, more advanced approaches, with a strong trend to date towards papers dealing with the placement of drug delivery in a biological context - a definite plus in my opinion.

So far all of the reviews have been of an exceptionally high technical quality, being critical, timely, thorough and well referenced. Many make absorbing reading. This is perhaps not surprising as many of the initial contributions have been written by members of a well-chosen editorial board. The technical standard is matched by a correspondingly high quality of presentation.

In addition to the established journals in the pharmaceutical sciences, several others have appeared over the past few years which would claim to cover one or more aspects of drug delivery. Among them are Pharmaceutical Research, CRC Critical Reviews of Therapeutic Drug Carrier Systems and Cancer Drug Delivery. Nonetheless, as long as Advanced Drug Delivery Reviews maintains its current quality and breadth, it has nothing to fear. It is an invaluable addition to the library of any serious investigator in drug delivery.

Drug development, from creation or discovery of an active substance, to its addition to the therapeutic armament of the prescribing physician, is a fascinatingly complex, risky but rewarding business. The high standing that society places on drug development is attested by the recent award of a Nobel prize to Sir Douglas Black for his role in the successful development of two important drugs, propranolol and cimetidine. So, when a new journal with the title Journal of Drug Development appears it is a matter of some interest. When, however, in its first commendable honesty, that he is unsure as to the scope and place of the journal, number the editor states, albeit with 